\title{
ANÁLISE QUALI-QUANTITATIVA DA ESPÉCIE Ligustrum lucidum W.T. Aiton NAS AVENIDAS DE CAMPO MOURÃO, PR
}

\author{
QUALI-QUANTITATIVE ANALYSIS OF Ligustrum lucidum W.T. Aiton ON THE \\ AVENUES OF CAMPO MOURÃO, PR
}

\begin{abstract}
Ana Flávia Bilmayer ${ }^{1}$, Grenda Costa Cordeiro Alves², Guilherme Redondo ${ }^{3}$, Igor José Malfetoni Ferreira ${ }^{4}$, Marcelo Galeazzi Caxambu ${ }^{5}$
\end{abstract}

\section{RESUMO}

A espécie Ligustrum lucidum, de origem asiática, tornou-se invasora por ser altamente adaptável as condições climáticas dos países da América do Sul. Introduzida com propósitos ornamentais na arborização urbana, tem ocasionado problemas nas florestas ombrófila mista com presença de araucária, na região sul do Brasil. Assim, este trabalho teve por objetivo analisar quali-quantitativamente a espécie L. lucidum nas principais avenidas de Campo Mourão, Paraná. A referida análise deu-se a partir da aplicação de uma lista de verificação para cada exemplar, levantando informações sobre localização, dimensões, conflitos com equipamentos urbanos (fiação, passeio público e espaço disponível para o desenvolvimento), poda e fitossanidade. Foram registrados 1037 indivíduos de $L$. lucidum em 16 das 18 avenidas em estudo e constatou-se que destes, 93\% apresentaram ao menos um conflito com algum equipamento urbano. Em relação à fitossanidade, obteve-se um total de 191 árvores classificadas como boas (18,4\%), 435 listadas como regulares (42\%) e 411 como ruins $(39,6 \%)$. Portanto, tendo em vista os diversos problemas com a infraestrutura urbana e fitossanidade abordados neste trabalho, conclui-se que o uso da espécie na arborização urbana pode ser considerado inapropriado.

Palavras-chave: Exótica invasora; Georreferenciamento; Conflitos com equipamentos urbanos.

\section{ABSTRACT}

The plant species Ligustrum lucidum is from Asian and has become invasive because of its highly adaptability to the climate conditions of south American countries. Widely introduced in public spaces for ornamental purposes in urban forestry, it has caused problems in Mixed Ombrophilous forests with araucaria in southern Brazil. Thus, the objective of this study was to quali-quantitatively analysis the Ligustrum lucidum species on the main avenues of Campo Mourão, Paraná. The analysis was based on the application of a checklist, containing information such as location, dimensions, conflicts with urban equipment (electricity and telephony, public walkway, available space for development and first bifurcation height), pruning and plant health for each of the specimen. It was registered 1037 Ligustrum lucidum in 16 of the 18 avenues evaluated and it was found that of these, $93 \%$ presented conflict with some of the urban equipment. Regarding plant health, it was classified 191 trees as good health (18.4\%), 435 trees as regular health (42\%) and 411 as bad health (39.6\%). Therefore, given the damage issues related to urban infrastructure and plant health covered in this study, the species may be considered inappropriate for urban forestry.

Keywords: Exotic invasive; Georeferencing; Urban equipment conflicts.

Recebido em 05.07.2017 e aceito em 11.09.2017

1 Estudante de graduação em Engenharia Ambiental da Universidade Tecnológica Federal do Paraná - UTFPR, Campo Mourão/PR. Email: ana-bilmayer@hotmail.com

2 Estudante de graduação em Engenharia Ambiental da UTFPR, Campo Mourão/PR. Email: grenda_cordeiro@hotmail.com 3 Estudante de graduação em Engenharia Ambiental da UTFPR, Campo Mourão/PR. Email: guilherme.r.redondo@gmail.com

4 Estudante de graduação em Engenharia Ambiental da UTFPR, Campo Mourão/PR. Email: igor_malfetoni@hotmail.com

5 Engenheiro Florestal. Professor da UTFPR, Campo Mourão/PR. Email: mgcaxambu@yahoo.com.br 


\section{INTRODUÇÃO}

A arborização em centros urbanos constitui-se como um serviço público estratégico na amenização de impactos ambientais adversos, principalmente associados às condições de artificialidade do meio urbano, além de aspectos ecológicos, históricos, culturais, sociais, estéticos e paisagísticos (SILVA et al., 2016). Dentre os benefícios da arborização urbana podem ser citados: a redução de calor, de poluição atmosférica e sonora; diminuição da velocidade dos ventos; projeção de sombras; embelezamento de vias públicas, canteiros e praças; proteção do solo; atração de avifauna, entre outros (SILVA et al., 2008). Entretanto, a escolha de espécies e locais inadequados pode gerar diversos conflitos, tornando este um aspecto relevante no plantio de árvores. Entre os possíveis problemas do plantio sem orientação técnica, têm-se a poda drástica, o corte raso e o plantio de espécies exóticas (RABER; REBELATO, 2010).

Segundo Periotto et al. (2016), podem ser observadas vantagens no plantio de espécies exóticas, especialmente no que se refere às características paisagísticas, esplendor e perfume de suas floradas e, por vezes, portes adequados. Porém, há um percentual excessivo desses indivíduos na arborização urbana, comprometendo a representatividade da flora local. Para Hoppen et al. (2014), as espécies invasoras são comumente implantadas na arborização de vias, parques, bosques e praças, frente ao desconhecimento das normas e da legislação existente, bem como o uso de espécies que se tornaram invasoras em ambientes com condições ecológicas semelhantes a do Brasil e que não deveriam ser implantadas.

Neste contexto, Ligustrum lucidum W.T. Aiton (Oleaceae), comumente conhecida como ligustro ou alfeneiro, foi amplamente introduzida com propósitos ornamentais em espaços públicos. De origem asiática, esta espécie torna-se frequentemente invasora por ser uma espécie altamente adaptável, com ocorrência natural registrada em diversos países da América do Sul. Na região sul do Brasil, L. lucidum começou a ser introduzido na arborização nas décadas de 60 e 70. A escolha da espécie foi considerada solução para arborização de vias públicas, devido à resistência às baixas temperaturas e ao rápido desenvolvimento. Entretanto, essas conclusões logo foram repensadas, uma vez que a utilização da espécie proporcionou uma rápida reprodução e colonização de novos ambientes (GUILHERMETTI et al., 2013).

Nas florestas de araucária, a espécie tornou-se particularmente problemática, pois pode formar densos capões, pressionando e inibindo espécies nativas. Os frutos são tóxicos aos seres humanos, provocando náuseas, dores de cabeça, pressão baixa e hipotermia. Porém, são atrativos aos pássaros, que os consomem sem sofrer efeitos negativos, disseminando as sementes em áreas naturais (MATTHEWS, 2005). 
Pode-se observar que a inserção de vegetação no meio urbano não é um processo simples, já que este meio não é o mais apropriado para as plantas. Inventários sobre a arborização das cidades são requisitos fundamentais para se traçar qualquer planejamento (SILVA et al., 2007). Cabe ao poder público municipal planejar e orientar a população em relação à ocupação do espaço urbano mediante estudos ambientais e atividades de sensibilização da importância das árvores à qualidade ambiental (RABER; REBELATO, 2010).

O presente trabalho teve por objetivo analisar qualiquantitativamente os indivíduos de L. Iucidum presentes nas principais vias públicas de Campo Mourão, Paraná.

\section{MATERIAL E MÉTODOS}

O município de Campo Mourão está localizado na região Noroeste do Paraná, na mesorregião Centro Ocidental do estado, cujas coordenadas geográficas são $23^{\circ} 57^{\prime} 10^{\prime \prime}$ e $24^{\circ}$ 18' 06" de Latitude Sul e $52^{\circ} 32^{\prime} 39^{\prime \prime}$ e 52 $11^{\prime}$ '08”' de Longitude Oeste (Figura 1).
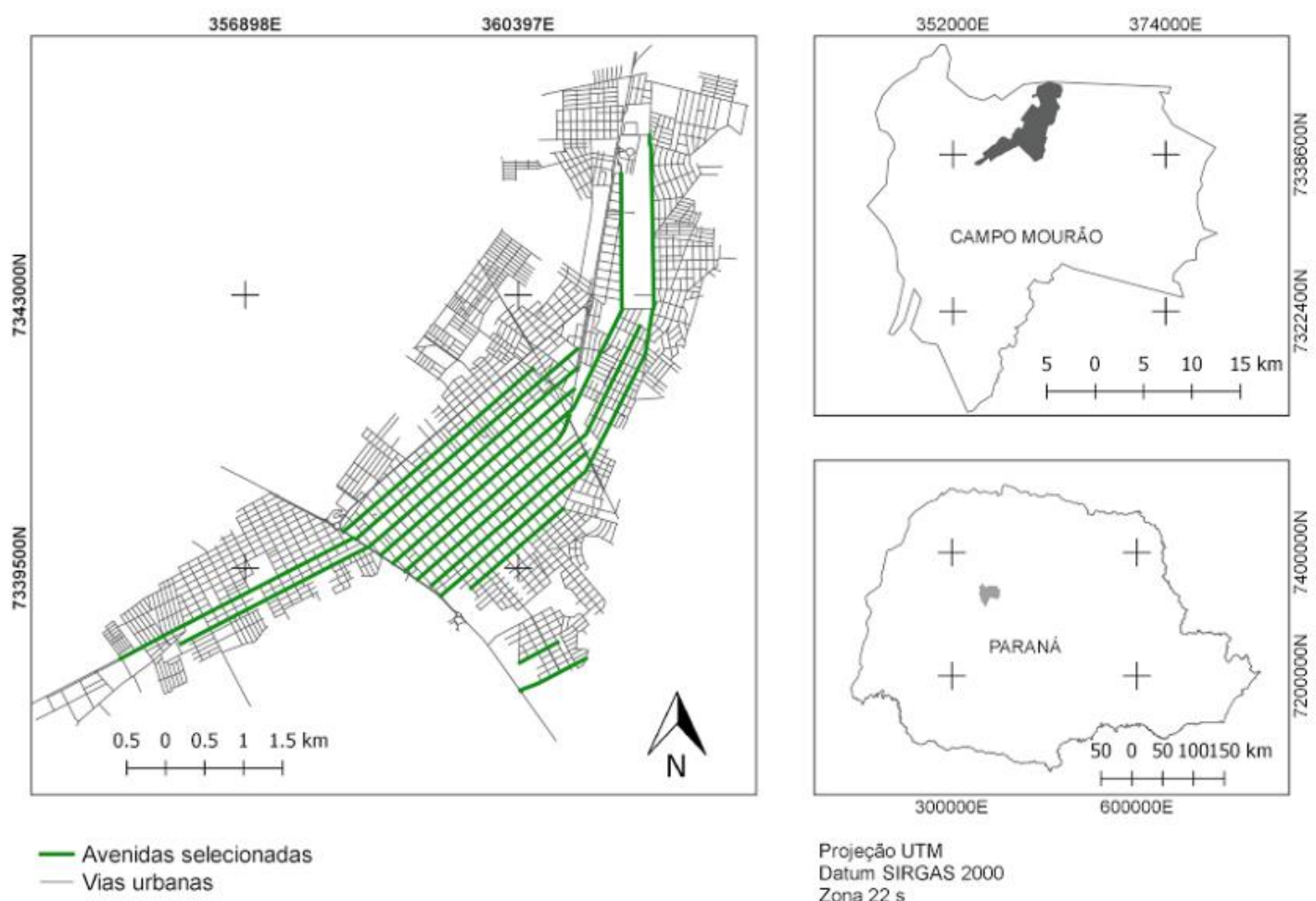

Figura 1. Localização das avenidas em estudo e as vias urbanas da cidade de Campo Mourão, PR Figure 1. Location of the studied avenues and urban ways of the municipality of Campo Mourão, PR

Campo Mourão está inserido na Bacia Hidrográfica do Rio Ivaí, em uma área de 735,3 km² (SEMA, 2013). O clima da região varia entre as classes Cfa (subtropical de verões quentes e chuvas bem distribuídas) e Cfb (clima oceânico com precipitações abundantes e bem 
distribuídas ao longo do ano), representado por faixas interativas entre Cfa/Cfb, Cfb/Cfa (ITCG, 2008).

Em relação à fitogeografia, na extensão territorial do município encontram-se áreas de Floresta Ombrófila Mista Montana (predomínio de aproximadamente 80\%), Floresta Estacional Semidecidual e uma parcela de Cerrado ( $8 \%$ do total em área do município), sobre a qual a cidade de Campo Mourão se desenvolveu (ITCG, 2009).

O levantamento de dados foi realizado através de caminhadas pelas 18 avenidas selecionadas para o estudo, principais vias públicas da cidade de acordo com o fluxo de veículos e pedestres. Elaborou-se uma lista de verificação aplicada na avaliação de cada exemplar da espécie, onde constavam informações sobre a localização por coordenadas geográficas obtidas a partir do aplicativo MAPS.ME®, o qual utiliza a base de dados do projeto OpenStreetMap e Sistema de Referência WGS 84; biometria (altura e Circunferência à Altura do Peito - CAP); conflitos com os equipamentos urbanos (rede elétrica e passeio público); espaço disponível para o desenvolvimento do espécime; altura da primeira bifurcação; poda e fitossanidade. Para o cálculo do CAP foram mensuradas e somadas todas as ramificações acima de 1,30 m dos indivíduos que apresentaram essa configuração.

Considerando as demais espécies, contabilizou-se apenas o número total de indivíduos, com o objetivo de se obter a representatividade de L. lucidum nas avenidas estudadas.

A lista de verificação foi elaborada conforme metodologias utilizadas em outros estudos na avaliação qualiquantitativa de espécies arbóreas, sendo as variáveis e os critérios descritos a seguir:

a) altura da primeira bifurcação: menor que $1,80 \mathrm{~m}$ ou maior que $1,80 \mathrm{~m}$ (GRACIANO-SILVA; CARDOSO-LEITE; TONELLO, 2015);

b) espaço disponível: menor que $1 \mathrm{~m}^{2}, 1 \mathrm{~m}^{2}$ ou maior que $1 \mathrm{~m}^{2}$, adaptado de Silva et al. (2008);

c) altura: até $5 \mathrm{~m}$ para pequeno porte, mais que $5 \mathrm{~m}$ e até $10 \mathrm{~m}$ para médio porte ou maior que $10 \mathrm{~m}$ para grande porte (FERRO et al., 2015);

d) poda: poda leve, corte de galhos de até $5 \mathrm{~cm}$ de diâmetro; poda pesada, maior que $5 \mathrm{~cm}$ de diâmetro (FERRO et al., 2015) ou poda drástica, supressão da copa da árvore;

e) fitossanidade: boa, para árvore sadia, sem sinais aparentes de ataque de insetos, doenças ou injúrias mecânicas, com pequena ou nenhuma necessidade de manutenção e forma ou arquitetura característica da espécie. Regular, para árvore em média condição de vigor, que necessita de pequenos reparos ou poda, apresenta leve descaracterização da forma e sinais de ataque de insetos, doença ou problemas fisiológicos. Ruim, avançado declínio, 
apresenta ataque severo de insetos, doença ou injúrias mecânicas, descaracterizando sua arquitetura ou desequilibrando o vegetal, adaptado de Aqua e Müller (2015).

O georreferenciamento dos indivíduos arbóreos foi realizado com o auxílio do aplicativo Qgis ${ }^{\circledR}$ para a elaboração dos mapas de distribuição conforme os conflitos com a fiação e com os equipamentos urbanos, além de um mapa para fitossanidade.

No mapa de conflitos com a fiação foram considerados os indivíduos localizados sob a fiação e, dessa forma, plotados aqueles que apresentaram algum tipo de interferência com a rede. Em relação ao mapa de conflitos com equipamentos urbanos considerou-se um padrão de cores a fim de expressar o somatório de equipamentos em conflito com cada indivíduo, em que foram classificados com:

a) verde: árvores que não apresentaram conflito com nenhum dos equipamentos urbanos;

b) amarelo: árvores que apresentaram conflito com um tipo de equipamento;

c) vermelho: árvores que apresentaram conflitos com dois ou três tipos de equipamentos;

d) vermelho escuro: árvores que apresentaram conflitos com todos os tipos de equipamentos avaliados.

Neste estudo, entendeu-se como equipamentos urbanos a fiação, calçamento, espaço disponível para o desenvolvimento arbóreo menor que um metro quadrado e altura da primeira bifurcação menor que $1,80 \mathrm{~m}$.

Para o mapa de fitossanidade foi considerado o registro da avaliação das condições fitossanitárias de cada indivíduo, como descrito anteriormente.

\section{RESULTADOS E DISCUSSÃO}

Em um universo amostral de 6480 indivíduos, 1037 indivíduos correspondem à espécie L. lucidum, representando $16 \%$ da arborização das avenidas em estudo. A espécie foi registrada em 16 das 18 avenidas analisadas (Tabela 1).

A porcentagem obtida de 16\% é expressiva, já que Santamour Júnior (1990) aponta que a predominância de uma única espécie não pode exceder $10 \%$ do total de espécies utilizadas na paisagem urbana, devido à possibilidade de supressão de espécies nativas e, principalmente, o aparecimento de pragas e doenças. Considerando o universo amostral deste estudo, a porcentagem obtida excede o recomendado pelo autor supracitado. 
Tabela 1. Levantamento de Ligustrum lucidum W.T. Aiton (Oleaceae) nas principais avenidas da cidade de Campo Mourão, PR, número de espécies encontradas e extensão aproximada da avenida

Table 1. Inventory of Ligustrum lucidum W.T. Aiton (Oleaceae) on the main avenues of Campo Mourão, PR, quantity of specimens found and approximately length of the avenue.

\begin{tabular}{lcc}
\hline \multicolumn{1}{c}{ Avenida } & $\mathbf{N}^{\circ}$ de espécimes & Extensão aproximada (km) \\
\hline Capitão Índio Bandeira & 180 & 3,0 \\
Manoel Mendes de Camargo & 156 & 3,0 \\
Jorge Walter & 123 & 3,2 \\
Goioerê & 99 & 3,3 \\
Guilherme de Paula Xavier & 95 & 3,7 \\
Irmãos Pereira & 78 & 2,9 \\
Comendador Norberto Marcondes & 72 & 3,5 \\
José Custódio de Oliveira & 67 & 2,5 \\
Presidente John Kennedy & 52 & 3,0 \\
João Bento & 50 & 2,4 \\
Manoel Nogueira & 29 & 2,6 \\
José Wierzchon & 11 & 1,5 \\
Prefeito Pedro Viriato de S. Filho & 10 & 1,1 \\
Ney Braga & 9 & 1,4 \\
Afonso Botelho & 4 & 1,6 \\
Armelindo Trombine & 2 & 2,3 \\
Álamos & 0 & 0,6 \\
Bosque & 0 & 0,5 \\
\hline
\end{tabular}

Em estudo realizado por Hoppen et al. (2014), os autores registraram um percentual de mais de $20 \%$ de espécies exóticas no levantamento do município de Farol - PR, sendo o $L$. lucidum a espécie mais representativa, com $63 \%$ de ocorrência dentre as exóticas encontradas. A espécie em estudo é a invasora mais frequente das 27 maiores cidades paranaenses (DELESPINASSE et al., 2011), invasora em fragmentos florestais do planalto sul catarinense (GUIDINI et al., 2014) e em praças e parques no Rio Grande do Sul (HUMMEL et al., 2014; TEIXEIRA et al., 2016).

Verificou-se que os menores indivíduos apresentaram valor de Diâmetro na Altura do Peito - DAP (obtido pela divisão do parâmetro CAP pelo valor de $\pi$ ) de 3,2 centímetros e o maior de 187,5 centímetros, evidenciando assim a existência de mudas recém-plantadas e indivíduos adultos de L. lucidum na arborização urbana. A média obtida entre os valores de DAP foi de 45,5 centímetros. Relacionado à circunferência arbórea, tem-se a altura, sendo constatados 593 indivíduos com alturas entre 5 e 10 metros (57,2\% de representatividade), 386 indivíduos com altura inferior a 5 metros $(37,2 \%)$ e 58 com alturas superiores a 10 metros $(5,6 \%)$.

A altura dos indivíduos está diretamente relacionada com eventuais conflitos na fiação devido ao desenvolvimento das árvores. Nas avenidas estudadas foram constatados $595 L$. lucidum sob fiação, dos quais 505 apresentaram interferência com a rede elétrica e de telefonia (Figura 2). 


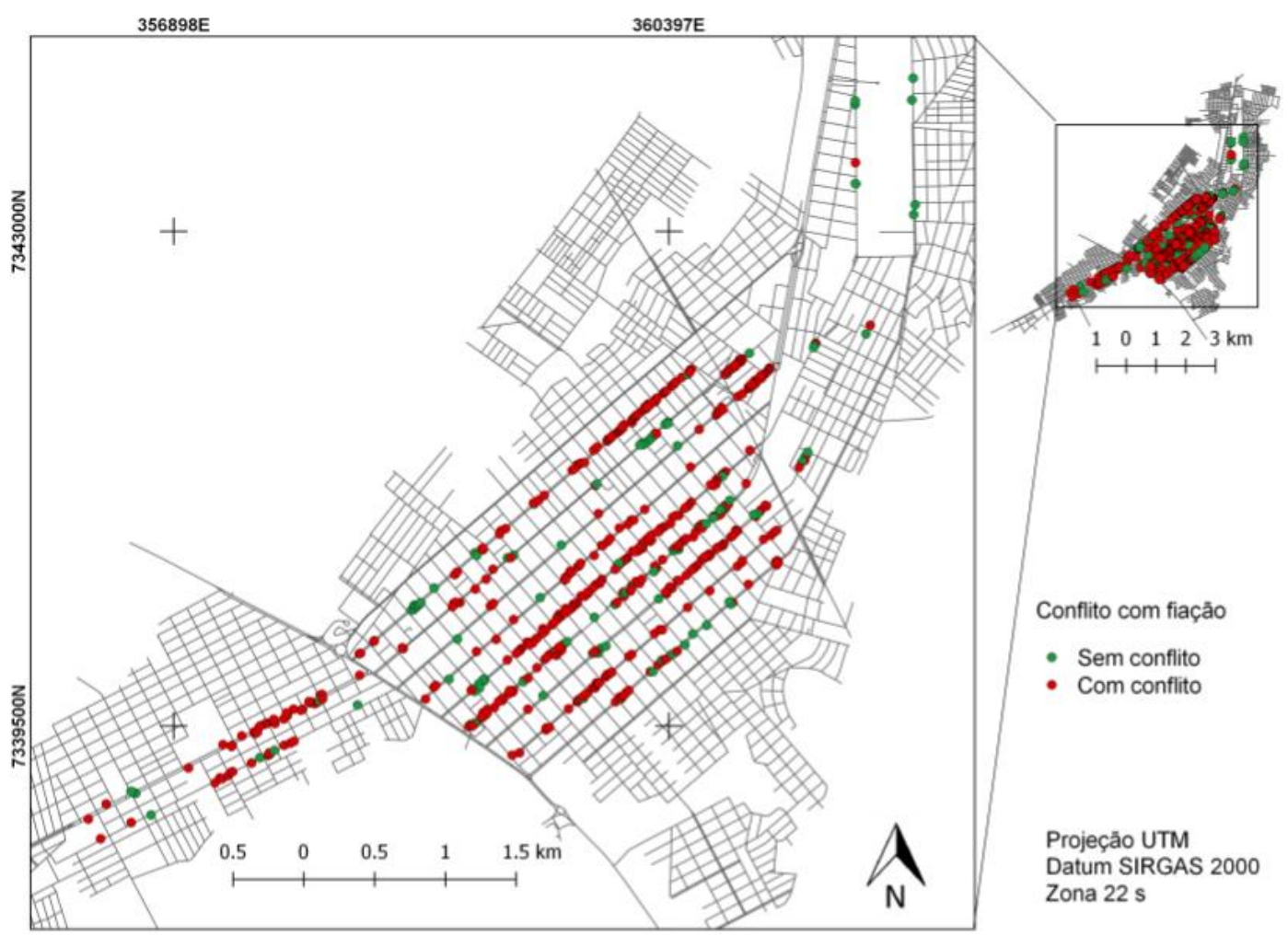

Figura 2. Distribuição de Ligustrum lucidum W.T. Aiton de acordo com o conflito com a fiação na cidade de Campo Mourão, PR

Figure 2. Distribution of Ligustrum lucidum W.T. Aiton according to the conflict with the electrical wiring in the city of Campo Mourão, PR

Contudo, a espécie em estudo é caracterizada como de crescimento rápido, atingindo até 15 metros de altura (INSTITUTO HÓRUS, 2017). Assim, constatou-se que, dos espécimes que apresentaram conflitos com a fiação, 365 árvores (72,3\%) possuem alturas entre 5 e 10 metros e 119 (26,6\%) apresentam alturas até 5 metros, demonstrando, portanto, a inadequação da espécie na arborização urbana para ambientes com presença de rede elétrica e de telefonia. Contudo, a ABNT NBR 5434 norteia a altura mínima para instalação de projetos de rede de fiação em vias urbanas, sendo $7 \mathrm{~m}$ para condutores primários e $4 \mathrm{~m}$ para condutores secundários (ABNT, 1982).

$\mathrm{Na}$ análise dos dados referentes ao espaço disponível para o desenvolvimento da espécie foi observado que 653 indivíduos se encontram em espaços maiores de $1 \mathrm{~m}^{2}$ (63\% de representatividade), já 363 em espaços com menos de $1 \mathrm{~m}^{2}$ (35\%) e 21 indivíduos com espaçamento delimitado em $1 \mathrm{~m}^{2}$ de área (2\%). Redin et al. (2010) consideram $1 \mathrm{~m}^{2}$ como o ideal para o desenvolvimento de árvores em vias públicas, com essa informação o somatório total de árvores com área igual a $1 \mathrm{~m}^{2}$ e maior que $1 \mathrm{~m}^{2}$, totalizaram $65 \%$ dos indivíduos contabilizados. Cabe ressaltar que dentre o montante de 1037 indivíduos, 417 localizam-se no canteiro central, que não dispõe de pavimentação e, por isso, não foram contabilizadas como problemáticas. 
Muitos problemas na arborização urbana foram motivados pela ausência de espaço apropriado para o desenvolvimento arbóreo. Durante o diagnóstico foram observados alguns locais que, por planejamento inadequado, desencadearam rachaduras e quebras ao calçamento (Figura $3 \mathrm{~A}$ ), e visando solucionar tal problema, notou-se que é comum a reforma das calçadas pelos moradores sem a preocupação com o espaço mínimo (Figura 3B).

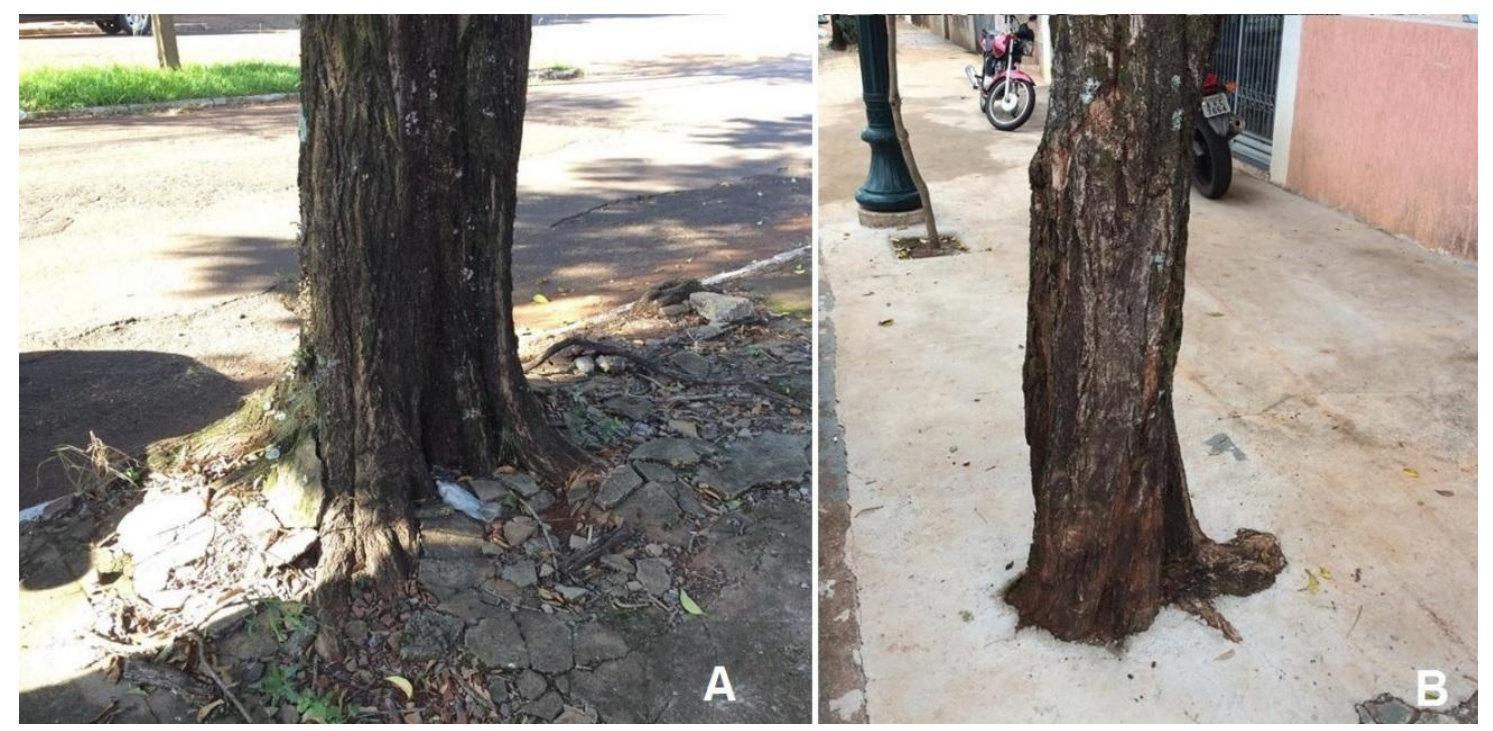

Figura 3. (A) quebra de calçada em função da inobservância as normas técnicas. (B) tronco em calçada reformada sem espaço para desenvolvimento, na cidade de Campo Mourão, PR

Figure 3. (A) sidewalk breakage due to lack of application of technical standards. (B) sidewalk reformed without space for tree development in Campo Mourão, PR

A altura da primeira bifurcação torna-se um parâmetro importante na arborização urbana, pois se relaciona ao livre acesso de pedestres e veículos. Graciano-Silva, CardosoLeite e Tonello (2015) recomendam o manejo de espécimes a fim de obter a altura da primeira bifurcação acima de $1,80 \mathrm{~m}$ para garantir que a projeção de galhos e copa não prejudique o passeio público. Observou-se que nas avenidas inventariadas 645 árvores (62,2\%) apresentaram bifurcação inferior ao recomendado, e 392 árvores $(37,8 \%)$ com bifurcação acima de 1,80 m. Segundo Silva et al. (2008), a ocorrência de indivíduos com bifurcação inferior a 1,80 m deve-se a ausência de poda de condução, a qual é responsável pela retirada de galhos e brotações da planta, garantindo seu crescimento retilíneo.

De modo geral, a maioria das árvores (93\%) analisadas apresentou pelo menos um conflito com algum tipo de equipamento urbano, ou seja, interferência com rede de distribuição de energia elétrica e telefonia, passeio público, espaço disponível para o desenvolvimento arbóreo e bifurcação inferior a 1,80 m (Figura 4). A arborização e os demais componentes urbanos disputam diariamente espaço físico e recursos para a sua manutenção. Esses conflitos podem ser minimizados por meio da poda executada com critérios técnicos e através 
da escolha de mudas adequadas para o plantio. A principal problemática para implantação apropriada da arborização urbana está em conciliar as espécies escolhidas com os componentes urbanos (PERIOTTO et al., 2016).

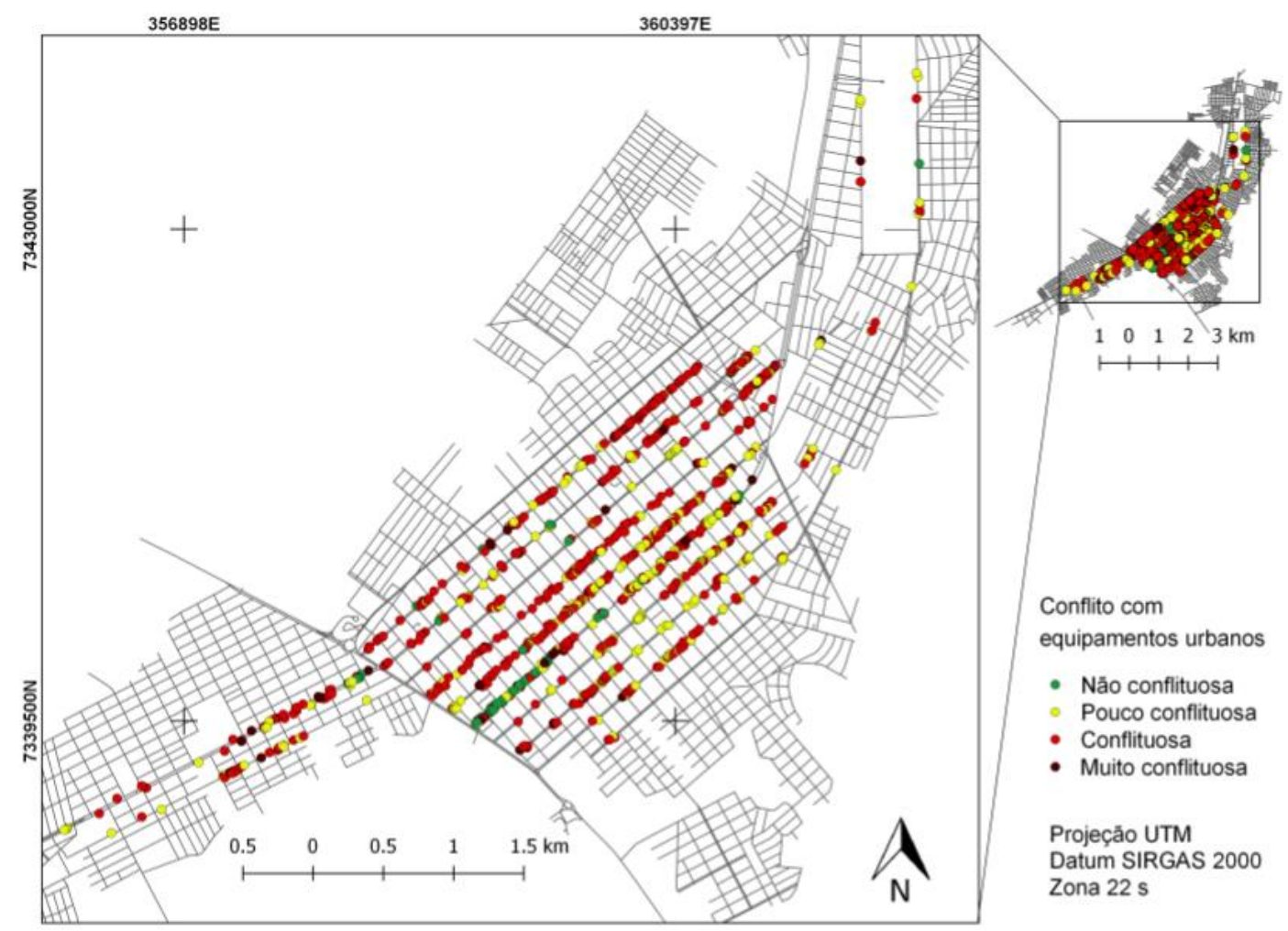

Figura 4. Distribuição de Ligustrum. lucidum de acordo com o conflito com os equipamentos públicos atribuído a cada espécime na cidade de Campo Mourão, PR

Figure 4. Distribution of Ligustrum. lucidum according to the conflicts with public equipment for each of the studied specimen in Campo Mourão, PR

Quanto ao critério de poda, foram observados 123 indivíduos (11,9\%) classificados como poda leve, 668 (64,4\%) elencadas como pesada e 246 (23,7\%) como drásticas. Verificou-se que dentre as árvores que sofreram poda pesada, 365 indivíduos (54,6\%) estavam sob fiação e apresentaram conflito com a mesma.

Em estudo realizado na cidade de Rio Grande, RS, por Damo, Hefler e Jacobi (2015), dos 1055 indivíduos arbóreos amostrados apenas 21,2\% apresentavam as copas sem podas. As demais árvores receberam poda drástica $(21,9 \%)$ ou outro tipo de poda avaliada no estudo (56,9\%). Já Martins, Andrade e De Angelis (2010), em um estudo na cidade de Luiziana, PR, além de constatarem a predominância da espécie $L$. lucidum no total de árvores inventariadas, observaram também que dentre as espécies que sofreram poda drástica, o ligustro foi a mais afetada pela técnica, com $67,3 \%$ dos casos, sendo que a soma de todas as demais espécies que sofreram este tipo de poda representa $10 \%$ do total das árvores contabilizadas no estudo. 
No diagnóstico de fitossanidade, 191 árvores foram classificadas como boas (18,4\%), 435 listadas como regulares (42\%) e 411 como ruins (39,6\%). Na análise espacial da distribuição de L. lucidum, de acordo com o parâmetro em questão, foram observados locais com maior ocorrência de árvores regulares e ruins (Figura 5). Essa concentração pode estar relacionada ao critério de poda considerado para a avaliação da fitossanidade das árvores, sendo a poda drástica a principal relação com o mal estado dos espécimes. De acordo com Silva et al. (2007), a poda drástica é uma técnica que, se empregada sucessivamente, acarreta na redução do tempo de vida dos espécimes, pois prejudica o desenvolvimento de pequenas raízes e sua capacidade de absorção de água e nutrientes. Outra possível consequência desta técnica é o apodrecimento de raízes, facilitando a infestação por cupins, o que ao longo do tempo coloca o indivíduo em risco de queda.

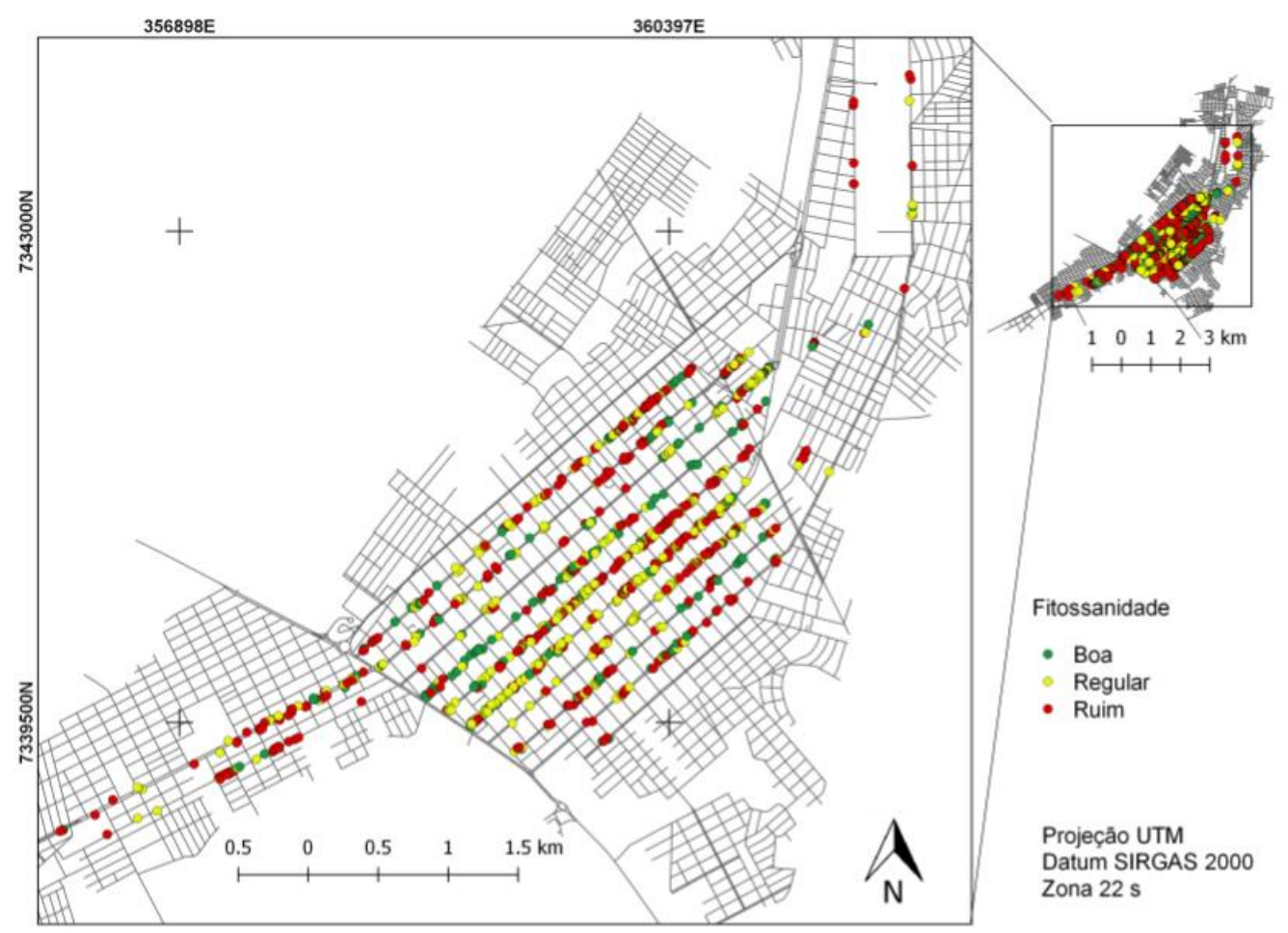

Figura 5. Distribuição de Ligustrum lucidum de acordo com a fitossanidade atribuída a cada espécime nas avenidas de Campo Mourão, PR

Figure 5. Distribution of Ligustrum lucidum according to the plant health for each of the studied specimen in Campo Mourão, PR

Para execução de poda eficiente é necessário utilizar técnicas específicas que não prejudiquem a planta, pois ao efetuá-la sem prudência os espécimes ficarão expostos ao ataque de micro-organismos, afetando negativamente a fitossanidade das árvores (MARTINS; ANDRADE; DE ANGELIS, 2010). 
O alto índice de indivíduos listados como ruins (40,1\%) demonstra a crítica situação da grande maioria dos exemplares de L. lucidum na cidade de Campo Mourão, acarretado, principalmente, por podas sem cuidados técnicos. Do total inventariado (1037 árvores), 23,7\% sofreram este tipo de poda.

\section{CONCLUSÕES}

A partir dos resultados obtidos neste estudo, conclui-se que o L. lucidum foi amplamente empregado na arborização das principais avenidas de Campo Mourão. Foi possível constatar que a espécie tem ocasionado diversos danos à infraestrutura urbana da cidade, como quebra do calçamento e problemas com a rede elétrica e de telefonia, evidenciando sua incompatibilidade com o meio. Portanto, recomenda-se a retirada paulatina desta espécie da arborização urbana.

\section{REFERÊNCIAS}

AQUA, M. D.; MÜLLER, N. T. Diagnóstico da arborização urbana de duas vias na cidade de Santa Rosa-RS. Revista da Sociedade Brasileira de Arborização Urbana, Piracicaba, v. 9, n. 3, p. 141-155, 2015.

ASSOCIAÇÃO BRASILEIRA DE NORMAS TÉCNICAS, "NBR 5434 - Redes de distribuição aérea urbana de energia elétrica", Rio de Janeiro, 1982.

DAMO, A.; HEFLER, S. M.; JACOBI, U. S. Diagnóstico da arborização em vias públicas dos bairros Cidade Nova e Centro na cidade de Rio Grande - RS. Revista da Sociedade Brasileira de Arborização Urbana, Piracicaba, v. 10, n. 1, p. 43-60, 2015.

DELESPINASSE, C. F. B.; HASSE, I.; SILVA, L. M.; CAMPESTRINI, F. Cenário da arborização urbana nas maiores cidades do estado do Paraná. Revista da Sociedade Brasileira de Arborização Urbana, Piracicaba, v. 6, n. 3, p. 149-171, 2011.

FERRO, C. C. da S.; OLIVEIRA, R. S.; ANDRADE, F. W. C; SOUZA, S. M. T. da R. Inventário quali-quantitativo da arborização viária de um trecho da rodovia PA-275 no município de Parauapebas-PA. Revista da Sociedade Brasileira de Arborização Urbana, Piracicaba, v. 10, n. 3, p. 73-84, 2015.

GRACIANO-SILVA, T.; CARDOSO-LEITE, E.; TONELLO, K. C. Inventário da arborização urbana no município de Araçoiaba da Serra, SP. Revista da Sociedade Brasileira de Arborização Urbana, Piracicaba, v. 9, n. 4, p. 151-169, 2015.

GUIDINI, A. L.; SILVA, A. C.; HIGUCHI, P.; DALLA ROSA, A.; SPIAZZI, F. R; NEGRINI, M.; FERREIRA, T. de S.; SALAMI, B.; MARCON, A. K.; JUNIO, F. B. Invasão por espécies arbóreas exóticas em remanescentes florestais no Planalto Sul Catarinense. Revista Árvore, Viçosa, v. 38, n. 3, p. 469-478, 2014. 
GUILHERMETTI, P. G. C.; VOGEL, G. F.; MARTINKOSKI, L.; FILEMOM, M. M. Aspectos da distribuição de Ligustrum lucidum WT Ainton em diferentes ecossistemas: Revisão bibliográfica. Revista Verde de Agroecologia e Desenvolvimento Sustentável, Mossoró, v. 8, n. 5, p. 171-176, 2013.

HOPPEN, M.; DIVENSI, H. F.; RIBEIRO, R. F.; CAXAMBÚ, M. G. Espécies Exóticas na Arborização de Vias Públicas no município de Farol, PR, Brasil. Revista da Sociedade Brasileira de Arborização Urbana, Piracicaba, v. 9, n. 3, p. 173-186, 2014.

HUMMEL, R. B.; COGHETTO, F.; PIAZZA, E. M.; TOSO, L. D.; DICK, G.; FELKER, R. M; ROVEDDER, A. P. M. Análise preliminar da invasão biológica por Ligustrum lucidum W. T. Aiton em unidade de conservação no Rio Grande do Sul. Caderno de Pesquisa, Santa Cruz do Sul, v. 26, n. 3, p. 14-26, 2014.

INSTITUTO DE TERRAS, CARTOGRAFIA E GEOLOGIA DO PARANÁ (ITCG). Mapa de Clima do Estado do Paraná. 2008. Escala base 1:2.000.000. Dísponível em: < http://www.itcg.pr.gov.br/arquivos/File/Produtos_DGEO/Mapas_ITCG/PDF/Mapa_Climas_A3.pd f>. Acesso em: 24 jun. 2017.

INSTITUTO DE TERRAS, CARTOGRAFIA E GEOLOGIA DO PARANÁ (ITCG). Mapa de Formações Florestais do Estado do Paraná. 2009. Escala base 1:2.000.000. Disponível em: $<$ http://www.itcg.pr.gov.br/arquivos/File/Produtos_DGEO/Mapas_ITCG/PDF/Mapa_Fitogeografi co_A3.pdf>. Acesso em: 24 jun. 2017.

INSTITUTO HÓRUS DE DESENVOLVIMENTO E CONSERVAÇÃO AMBIENTAL. Base de dados nacional de espécies exóticas invasoras. Florianópolis. Disponível em: <http://i3n.institutohorus.org.br>. Acesso em: 25 jun. 2017.

MARTINS, L. F. V.; ANDRADE, H. H. B. de; DE ANGELIS, B. L. D. Relação entre podas e aspectos fitossanitários em árvores urbanas na cidade de Luiziana, Paraná. Revista da Sociedade Brasileira de Arborização Urbana, Piracicaba, v. 5, n. 4, p. 141-155, 2010.

MATTHEWS, S. América do Sul invadida: a crescente ameaça das espécies exóticas invasoras. GISP- Global Invasive Species Programme, Nairobi, 80 p, 2005.

PERIOTTO, F.; PITUCO, M. M.; HELMANN, A. C.; SANTOS, T. O. dos; BORTOLOTTI, S. L. Análise da arborização urbana no município de Medianeira, Paraná. Revista da Sociedade Brasileira de Arborização Urbana, Piracicaba, v. 11, n. 2, p. 59-74, 2016.

RABER, A. P.; REBELATO, G. S. Arborização viária do município de Colorado, RS-Brasil: análise quali-quantitativa. Revista da Sociedade Brasileira de Arborização Urbana, Piracicaba, v. 5, n. 1, p. 183-99, 2010.

REDIN, C. G.; VOGEL, C.; TROJAHN, C. D.; GRACIOLI, C. R.; LONGHI, S. J. Análise da arborização urbana em cinco praças do município de Cachoeira do Sul, RS. Revista da Sociedade Brasileira de Arborização Urbana, Piracicaba, v. 5, n. 3, p. 149-164, 2010.

SANTAMOUR JÚNIOR, F.S. Trees for urban planting: diversity uniformity, and common sense. In: METRIA CONFERENCE, 7., 1990, Lisle. Proceedings... Lisle: 1990. p. 57-66.

SECRETARIA DE ESTADO DO MEIO AMBIENTE E RECURSOS HÍDRICOS (SEMA). Bacias hidrográficas do Paraná. Série Histórica. Mauri César Barbosa Pereira e José Luiz Scroccaro (Org.). 2 ed. Curitiba, PR, 138 p, 2013. 
SILVA, K. A. R. da; LELES, P. S. dos S.; GIÁCOMO, R. G.; MENDONÇA, B. A. F. de. Diagnóstico e uso de geoprocessamento para manejo da arborização urbana do bairro centro da cidade do Rio de Janeiro-RJ. Revista da Sociedade Brasileira de Arborização Urbana, Piracicaba, v. 11, n. 4, p. 98-114, 2016.

SILVA, L. M.; HASSE, I.; CADORIN, D. A.; OLIVEIRA, K. A.; OLIVEIRA, F. A. C.; BETT, C. F. Inventário da arborização em duas vias de Mariópolis/PR. Revista da Sociedade Brasileira de Arborização Urbana, Piracicaba, v. 3, n. 1, p. 36-53, 2008.

SILVA, L. M.; MOCCELIN, R.; WEISSHEIMER, D. I.; ZBORALSKI, A. R.; FONSECA, L.; RODIGHIERO, D. A. Inventário e sugestões para arborização em via pública de Pato Branco/PR. Revista da Sociedade Brasileira de Arborização Urbana, Piracicaba, v. 2, n. 1, p. 101-108, 2007.

TEIXEIRA, I. F.; FIGUEIREDO, F. M. de; TABORDA, I. G. R.; SOARES, L. M. Análise fitossociológica da Praça Camilo Miércio no centro histórico de São Gabriel, RS. Revista da Sociedade Brasileira de Arborização Urbana, Piracicaba, v. 11, n. 1, p. 01-13, 2016. 